\title{
Uma Análise da Utilização de Redes Sociais no Ensino de Língua Estrangeira em Turmas do Ensino Médio
}

\author{
Maria Aélia de Sousa Vieira ${ }^{1}$, Emmanuel Sávio Silva Freire ${ }^{2}$
}

${ }^{1}$ Polo de Apoio Presencial - Universidade Estadual do Ceará (UECE)

Caixa Rua Padre Argemiro Rolim de Oliveira, s/n - 63.210-000 - Mauriti - CE - Brasil

${ }^{2}$ Departamento de Ensino - Instituto Federal do Ceará (IFCE)

Morada Nova - CE - Brasil

ahelha.sousa@gmail.com, savio.freiredifce.edu.br

\begin{abstract}
The Information and Communication Technologies (ICT) are inserted in the various sectors. In the face of this, it was sought social networks, the spaces for people who interact and in matters of interest, and it was created a community on Facebook, with the intention of maintaining an interaction, sharing one of the disciplines of Foreign Languages (English / Spanish). Thus, the objective of this work was to analyze the use of new technologies in high school classes, using the social network Facebook. Seventeen high school students and five foreign language teachers (English / Spanish) attended the high school. A bibliographical research and a field study were carried out to arrive at the result. In the question, it is possible to perceive the possibility of ICT as pedagogical support for activities in the classroom, as well as for the realization of autonomous and continuous studies in the acquisition and improvement of knowledge.
\end{abstract}

Resumo. As Tecnologias de Informação e Comunicação (TIC) se encontram inseridas em diversos setores. Diante disto, buscou-se as redes sociais, espaços acolhedores de pessoas que interagem e partilham diversos assuntos em comum, e criou-se uma comunidade no Facebook, com o intuito de manter a interação, o compartilhamento e a colaboração dos alunos das disciplinas de Línguas Estrangeiras (inglês/espanhol). Assim, o objetivo deste trabalho foi analisar a utilização das novas tecnologias no ensino de língua estrangeira em turmas do ensino médio, utilizando a rede social Facebook. Participaram desse estudo dezesseis alunos do ensino médio e cinco professores de línguas estrangeiras (inglês/espanhol). Realizou-se uma pesquisa bibliográfica e um estudo de campo para chegar ao resultado. No qual, percebe-se as possibilidades que as TIC oferecem como suporte pedagógico para atividades em sala de aula, bem como para realizar estudos autônomos e contínuos na aquisição e aperfeiçoamento de conhecimentos.

\footnotetext{
${ }^{1}$ Professora da Escola de Ensino Médio Eunice Maria de Sousa Freitas. Licenciada em Informática pela Universidade Estadual do Ceará (UECE) e mestre em Ciências da Educação.

2 Professor do Instituto Federal do Ceará (IFCE/Campus Morada Nova), e colaborador do curso de Licenciatura em Computação da UECE. Mestre em Ciências da Computação.
} 
VII Congresso Brasileiro de Informática na Educação (CBIE 2018)

Anais dos Workshops do VII Congresso Brasileiro de Informática na Educação (WCBIE 2018)

\section{Introdução}

A tecnologia vem modificando a comunicação e o modo de vida das pessoas ao longo dos anos. Segundo [Lévy 1993], a humanidade se encontra em uma "época limítrofe", ou seja, uma transição entre a civilização baseada na escrita e na lógica por ela fundadas e desenvolvidas, e a civilização informática. Nesse contexto, as Tecnologias de Informação e Comunicação (TIC) surgem como recursos educativos, não somente no sentido de ser uma solução para o problema da educação, tais como: compreensão de textos simples, resolução de cálculos matemáticos básicos, conhecimento elementar da química, física, entendimento de uma segunda língua entre outros; mas como ferramenta auxiliar inovadora, considerando a rápida transição do livro para a televisão e o vídeo, e destes para o computador e a internet, sem o devido domínio e exploração de todas as possibilidades de cada meio [Moran, Masetto e Behrens 2000].

Com isso, o uso das TIC impõe aos docentes um conhecimento mais abrangente tanto na parte técnica quanto na utilização pedagógica, pois tais competências, de acordo com Parâmetros Curriculares Nacionais do Ensino Médio (PCNEM) [LDB, Lei n 9.394 , de 1996], devem estar integradas para que não sirvam apenas para informar, mas para contribuir no processo de construção de conhecimento nas diversas áreas. Neste contexto, vários estudos [Warschauer 2014] [Leffa 2014] [Chapelle 2003] apresentaram que a inclusão de novas tecnologias não pode ser aplicada sem planejamento no contexto escolar. Assim, o professor precisa passar por uma capacitação para saber utilizá-las tecnicamente e explorá-las pedagogicamente com seus alunos.

Além disso, a internet aumentou as possibilidades de interação comunicativa e reflexões sobre o uso da linguagem no mundo contemporâneo e, por meio do conhecimento colaborativo, facilitar e ampliar o entendimento entre os aprendizes. Consequentemente, a comunicação entre as pessoas torna-se mais acessível, não importando o tempo ou o espaço em que elas estejam. O surgimento de novos meios comunicacionais e informacionais (computador, internet e WEB 2.0) possibilitou uma maior interação das áreas de conhecimento [Tajra 2002]. Quanto ao uso dessas tecnologias no ensino e aprendizagem de língua estrangeira, perceber-se que há diferentes plataformas (Moodle, Teleduc, Livemocha, BBC Languages etc.) e outros recursos pedagógicos tais como chats, fóruns, wikis e blogs que são utilizados para o enriquecimento da língua, oportunidades de comunicação com aprendizes/nativos e conhecimento de diversas culturas de outras partes do mundo.

Vale ressaltar que os PCNEM, em consonância com a Lei de Diretrizes e Bases (LDB), relatam que o ensino de Línguas Estrangeiras Modernas recuperou, de alguma forma, a importância que durante muito tempo lhes foi negada, antes considerada pouco relevante, agora se apresenta como importante disciplina para a formação do cidadão. Conforme o Inciso III do Art. 36 afirma que "será incluída uma língua estrangeira moderna, como disciplina obrigatória, escolhida pela comunidade escolar, e uma segunda, em caráter optativo, dentro das disponibilidades da instituição".

Atualmente, devido a todos esses artefatos tecnológicos que o aluno dispõe, torna-se difícil insistir em ministrar aulas somente por meio de tecnologias rudimentares. Logo, não há como desvincular o ensino de línguas estrangeiras da nova realidade tecnológica. Talvez, muitos professores não façam uso dessas tecnologias por não acreditarem no efeito positivo que estas podem surtir no processo de ensino 
VII Congresso Brasileiro de Informática na Educação (CBIE 2018)

Anais dos Workshops do VII Congresso Brasileiro de Informática na Educação (WCBIE 2018)

aprendizagem. Talvez a falta de experiência em utilizá-las, os levem a proferir tal discurso como desculpa para não incorporar tal prática.

Dessa forma, a motivação para realização de uma pesquisa dentro do tema relativo ao uso das tecnologias pelos professores de Língua Estrangeira no processo ensino e aprendizagem surge da observação e do interesse em descobrir a eficácia dessas ferramentas na aprendizagem de uma segunda língua. Logo, objetivo deste estudo consiste em analisar verificar se o processo de ensino e aprendizagem de línguas estrangeiras é facilitado pela utilização de comunidades em redes sociais (Facebook). Uma vez que, as TIC favorecem a aproximação de pessoas de diferentes países, disponibiliza uma diversidade de materiais para auxiliar e fortalecer a aprendizagem de conteúdos em sala de aula; oferecem várias páginas na web para realização de cursos, prática do idioma através da audição de textos, leitura, escrita, fala, visualização de vídeos, músicas, facilitam uma aprendizagem autônoma. Adicionalmente, os alunos, por meio da rede social, podem interagir uns com os outros para praticar os conteúdos vistos em sala de aula.

Este artigo está organizado como segue. As seções 2 e 3 apresentam os conceitos sobre as redes sociais e o Facebook, respectivamente. Os trabalhos relacionados são retratados na seção 4 . Na seção 5 , a metodologia utilizada nessa pesquisa é detalhada. Os resultados obtidos são discutidos na seção 6 . Na seção 7 , as considerações finais são expostas. Finalmente, os agradecimentos são apresentados na seção 8.

\section{Redes Sociais}

As redes sociais são ambientes constituídos por pessoas ou organizações desenvolvidas para prover a comunicação, colaboração e partilha de conteúdos através de redes de contatos. Também chamadas de comunidades, as redes sociais permitem a troca de experiências e integração de usuários conectados por diferentes tipos de relação e interesses em comum.

De acordo com [Faria e Silva 2012], as redes sociais lançam recursos que podem ser utilizados por professores e alunos para juntos construírem ambientes educacionais. Apontam como vantagem, os usuários conseguirem compartilhar os trabalhos entre si sem a necessidade de estar no ambiente escolar. Estes autores concordam com pesquisas atuais, que defendem o estudo de línguas em ambientes colaborativos que proporcione a autonomia do aluno oportunizando a construção do conhecimento.

Segundo [Mattar 2013], com o crescimento das TIC, da internet, da WEB 2.0 e da inserção dos usuários nas redes sociais, a educação começou a ser introduzida nesses ambientes. Isso devido à facilidade da interação que acontece entre as pessoas, simultaneamente ou não. Além disso, os nativos digitais que cresceram nessa geração se utilizam desses ambientes para se comunicar, estudar e trabalhar em rede. Logo, essas redes são espaços abertos e colaborativos que permitem ao aluno ser além de receptor, construtor de seu conhecimento.

\section{Facebook}

Lançado em 2004, o Facebook atingiu a marca de 1 bilhão de usuários ativos, em 2012. De acordo com [Finardi e Veronez 2013], este foi um dos motivos que levaram os estudiosos a investigar como essa poderosa ferramenta poderia ser usada no campo da educação. Apesar das redes sociais virtuais não terem sido projetadas para uso 
VII Congresso Brasileiro de Informática na Educação (CBIE 2018)

Anais dos Workshops do VII Congresso Brasileiro de Informática na Educação (WCBIE 2018)

educacional, as pessoas que as utilizam podem direcioná-las para a área de seus interesses. A partir do momento que os alunos do Ensino Médio utilizam o Facebook para compartilhar conteúdos, vídeos, interagir com seus colegas, colaborar nas atividades, adotar como um local de estudo, esse espaço passa a ser educacional. "Os softwares em que se estabelecem essas redes [sociais] não foram produzidos para uso em educação, mas acabam sendo utilizados tanto como ensino como para aprendizagem" [Mattar 2013 apud Joaquim 2014].

Além disso, o Facebook proporciona várias possibilidades de interação para o uso pedagógico entre os grupos, cabendo à escola e professor adaptar a seus objetivos [Mattar 2013]. Assim, estudos direcionados as possibilidades que o Facebook oferece ainda são limitados [Joaquim 2014], mas algumas pesquisas [Patrício e Gonçalves 2010] [Minhoto 2012] [Brescia 2013] [Mattar 2013] avaliam o Facebook como ferramenta de aprendizagem colaborativa. Para [Minhoto 2012 apud Joaquim 2014], “o Facebook é adequado para apoiar o ensino presencial [...]; o Facebook permite a criação de um contexto que potência a aprendizagem colaborativa [...]; a utilização do Facebook refletese na dinâmica da aprendizagem". Neste sentido, os pesquisadores [Patrício e Gonçalves 2010 apud Joaquim 2014] afirmam que o Facebook "transformou-se não só num canal de comunicação e um destino para as pessoas interessadas em procurar, partilhar ou aprender sobre determinado assunto, mas igualmente um meio de oportunidade para o ensino".

Com isso, infere-se que apesar de haver poucos estudos relacionados com as possibilidades que a rede social Facebook pode oferecer, as pesquisas apontam como positiva a utilização dessa comunidade para auxiliar o ensino presencial, e instigar a produção colaborativa por ser um ambiente dinâmico. [Sturgeon e Walker 2009 apud Finardi e Veronez 2013] defendem o Facebook como resultado positivo na interação aluno-professor nas relações intelectuais e sociais, atuando como ponte entre a comunicação on-line e off-line. Adicionalmente, [Mattar 2013] sugeriu o uso de ferramentas do Facebook na educação, como Grupos, Slide Share e Perguntas, com possibilidades de utilização como um Ambiente Virtual de Aprendizagem (AVA). Em relação ao ensino de línguas, [Finardi, Presbianca e Momm 2013] recomendaram que o melhor enfoque para ensino de língua estrangeira fosse uma mistura de recursos assistidos por computador (on-line) e aulas tradicionais ensinadas por professores, criando um ambiente de aprendizado combinado.

\section{Trabalhos Relacionados}

Nesta seção, são apresentados os trabalhos correlatos com o objetivo da presente pesquisa. Para tanto, foram considerados trabalhos que utilizaram redes sociais como facilitadores no ensino de língua estrangeira.

A pesquisa de [Finardi e Veronez 2013] demonstrou resultados sobre as crenças de professores e alunos sobre o uso do Facebook na educação, como ferramenta de comunicação e aprendizagem de língua estrangeira. Além disso, sugeriu maneiras de uso desse recurso para apoiar o aprendizado de língua estrangeira e as possibilidades em relação ao tempo, ao espaço e à interação de modo significativo e interessante. Entretanto, advertiu sobre não oferecer meio de pesquisa de conteúdo específico e da dificuldade de acompanhar os tópicos anteriores e avaliar o progresso dos alunos na aquisição da segunda língua. 
O trabalho de [Silva 2014] apresentou a rede social Facebook como um ambiente para o ensino e aprendizagem de Língua Espanhola tanto dentro como fora da sala de aula. Essa rede social foi escolhida por ser considerado um ambiente muito acessado pelos alunos e conter recursos que facilitam a interação, o compartilhamento de conteúdo e autonomia dos usuários. Como resultados, foram encontrados que o Facebook apresenta características intrínsecas a $\mathrm{EaD}$ e os professores precisam repensar sua prática para que os estudantes não os ultrapassem, uma vez que permanecem mais tempo com as tecnologias e mais predispostos a desenvolverem o seu cognitivo para a área digital.

A investigação de [Berwanger e Sabadin 2014] utilizou o Facebook para apoiar o ensino de língua inglesa no ensino médio. Para tanto, foi organizada uma página no Facebook para a interação entre os alunos e resolução de atividades. Por meio de aplicação de questionário, as pesquisadoras evidenciaram que os alunos conseguem utilizar a rede social e as TIC no seu cotidiano de forma satisfatória, porém não apresentam a mesma desenvoltura ao utilizá-los no contexto educacional.

Ao comparar o objetivo do presente trabalho com os relacionados, percebe-se que ainda são necessários estudos que analisem o Facebook como ambiente facilitador para o ensino de línguas estrangeiras.

\section{Metodologia}

O presente estudo buscou confirmar se é produtiva, para a aprendizagem dos alunos de línguas estrangeiras, a utilização de redes sociais. Portanto, criou-se comunidades no Facebook, para a interação, compartilhamento de conteúdo e colaboração de atividades entre os membros do grupo. Dessa forma, uma turma de segundo ano do ensino médio com dezesseis alunos foi convidada a participar de duas comunidades (Inglês/Espanhol) e assim, responder perguntas referentes ao estudo das línguas inglesa e espanhola em sala de aula e com o auxílio de comunidades no Facebook destinadas a um melhor aprendizado das línguas. Aos cinco professores que lecionam nessas disciplinas, foi pedido para responder questionários referentes a sua prática e visão sobre o uso desses recursos como aliados no processo pedagógico.

A metodologia qualitativa permitiu que alunos e professores refletissem sobre a utilização e aproveitamento das redes sociais para o fortalecimento da aprendizagem nos alunos das disciplinas de línguas estrangeiras. Vale ressaltar que participou dessa coleta de informações apenas uma turma (dezesseis alunos) que utilizava previamente o Facebook para interação social, porém foi explicado aos estudantes que eles iriam compartilhar conteúdos, conhecimentos, interagirem com os colegas de sala de aula via Facebook como suporte de aprendizagem. Esses alunos eram oriundos da Escola de Ensino Médio Eunice Maria de Sousa Freitas situada em Mauriti/CE enquanto os professores estavam lotados em diferentes escolas estaduais desse município.

De início, foi acertado com a escola, com os alunos e comunicado aos pais que seriam necessários quatro encontros à noite, na referida escola, para ser ministradas aulas referentes às disciplinas de inglês e espanhol (encontros presencias). Além disso, a comunicação para envio e recebimento de matérias para intensificar o estudo e acompanhar o desenvolvimento das atividades seriam realizados por meio da comunidade no Facebook, criada especialmente para esse momento. Criou-se também um e-mail coletivo para que houvesse a troca de materiais e servisse para tirar dúvidas, 
caso surgisse, no período da investigação. No primeiro encontro, foi apresentado o objetivo dessas reuniões e da participação dos alunos na comunidade virtual. Para a realização da pesquisa, utilizou-se questionários ao iniciar e finalizar o estudo. $\mathrm{O}$ objetivo era obter informações e opiniões dos alunos sobre o uso do Facebook como espaço educacional. Adicionalmente, outro questionário foi enviado para seis professores de línguas, porém somente cinco devolveram.

As questões preparadas para os alunos buscavam-se investigar sobre o conhecimento que eles tinham em relação ao computador, sua utilização como recurso educacional, seu conhecimento sobre as comunidades virtuais com fim pedagógico. Buscou-se saber de que modo acontecia à acessibilidade e ao uso dos recursos tecnológicos por eles, e como essas ferramentas eram vistas e utilizadas para a aprendizagem de um idioma. Além disso, realizou-se aulas presenciais para observar o desempenho e a participação em sala de aula bem como nas comunidades de estudo. Para os professores, produziu-se questões a fim de conhecer a prática pedagógica do docente, as dificuldades que eles encontram para lecionar línguas, quais recursos tecnológicos auxiliam seu trabalho em sala, se possuíam formação para utilizar as TIC e como as via no processo de ensino e aprendizagem, em especial, o Facebook.

\section{Resultados e discussões}

Esta seção apresenta os resultados coletados a partir dos questionários aplicados aos alunos e professores acerca da utilização do Facebook para o ensino de língua estrangeira.

\subsection{Análise dos Questionários Respondidos pelos Alunos}

Inicialmente, aplicou-se um questionário para dezesseis alunos com oito perguntas. Essas perguntas estavam relacionadas à utilização de livros didáticos, de dicionários, de aparelhos de CD, de computadores, de internet, de TV e DVD e do Laboratório Escolar de Informática (LEI) durante as aulas de língua estrangeira. Além disso, tentou-se identificar o perfil dos alunos sobre os hábitos de estudo, os conhecimentos acerca da utilização de computadores e da internet, se utilizavam o computador como recurso educacional e se acreditavam que o uso de comunidades de línguas estrangeiras poderia facilitar a aprendizagem.

Diante das respostas coletadas, foi possível perceber que o livro didático liderou em relação ao uso de recursos em sala de aula, em seguida o uso do dicionário. A pesquisa mostrou que a escola possui um LEI, mas raramente é utilizado para ensino de línguas. Conferiu-se que quase metade dos alunos não tem o hábito de estudar diariamente, e que foi unânime o acesso deles à internet, porém nem sempre para fins educacionais. Comprova-se pelas respostas dos alunos que a 93,7\% deles acreditavam que a participação em comunidades de línguas estrangeiras poderia facilitar a aprendizagem.

Durante a investigação realizou-se encontros presenciais e os alunos fizeram atividades, tiveram conhecimento das comunidades (Inglês/Espanhol) no Facebook. Foram sugeridos materiais, sites, exercícios on-line, vídeos relacionados com o assunto, no entanto, o resultado não foi satisfatório, apesar de acreditarem que poderia acontecer aprendizagem ao interagir em comunidades em rede social. Após três encontros, um 
VII Congresso Brasileiro de Informática na Educação (CBIE 2018)

Anais dos Workshops do VII Congresso Brasileiro de Informática na Educação (WCBIE 2018)

novo questionário foi aplicado: a primeira pergunta questionou a respeito da utilização de comunidade/blog/redes sociais; a percepção dos alunos em relação ao melhoramento da aprendizagem, e 87,5\% dos alunos afirmaram que ocorreu. A segunda questão estava relacionada ao recurso tecnológico mais produtivo e $81,3 \%$ indicaram a internet, $12,5 \%$ as redes sociais e $6,3 \%$ o WhatsApp.

Em relação às atividades realizadas via Facebook, 81,3\% dos alunos afirmaram que foram boas e interessantes, $12,5 \%$ acharam regulares e $6,2 \%$ não soube responder. Em relação ao entendimento do conteúdo: $75 \%$ afirmaram que era mais interessante, ajudava a aprender mais, que a partir das redes melhorava o conteúdo, era um meio mais dinâmico e criativo, porque chamava a atenção do aluno e era menos tedioso, mas $25 \%$ informou que não colaborou. Sobre a preferência de atividades em sala de aula ou via rede social, $75 \%$ alunos preferiram a sala de aula por entenderem melhor, por ter um professor orientando, $18,7 \%$ responderam na rede social por ser mais dinâmica, por aprender mais e $6,3 \%$ acredita que o trabalho em grupo facilita mais a aprendizagem, $6,3 \%$ aluno respondeu que há um aproveitamento melhor das duas formas. A respeito da avaliação da atividade em rede social; $75 \%$ disseram que era boa, 18,7\% opinaram ser regular e 6,3\% classificou como excelente. A última questão questionou se o aluno considerava que havia mais aproveitamento em sala de aula normal ou através de comunidade via rede social. Assim, 81,3\% responderam que sala de aula/normal e $18,7 \%$ disseram através de comunidade/via rede social.

Pode-se inferir que esses alunos, apesar de terem acesso à internet, participarem da rede social Facebook, ainda não a veem como espaço para estudo/aprendizagem. Esse resultado corrobora com a pesquisa de [Berwanger e Sabadin 2014], pois os alunos não apresentaram uma boa desenvoltura por estar inseridos no contexto educacional. Entretanto, a utilização da rede social juntamente com as aulas presenciais poderia auxiliar o processo de ensino e aprendizagem, pois o aluno tem curiosidade e interesse nas atividades desenvolvidas no computador. Em outras palavras, a rede social assemelha-se a um ambiente virtual de aprendizagem utilizado na modalidade $\mathrm{EaD}$, como evidenciado por [Silva 2014]. Além disso, para uma melhor abordagem para ensino de língua estrangeira é necessária uma mistura de recursos on-line e aulas presenciais, administradas pelo professor [Finardi, Presbianca e Momm 2013]. Com isso, necessita-se que o professor adquira uma nova postura e adicione a suas aulas o uso de comunidades para extensão do seu trabalho e acompanhamento pedagógico dos seus alunos [Silva 2014].

Vale ressaltar, que para a utilização das novas tecnologias, o professor deve inserila no planejamento de suas aulas, abordando como um instrumento facilitador do processo de aprendizagem, principalmente, de línguas. Por meio do resultado dos questionários, pode-se inferir que apenas a tecnologia em si, não traz a mesma sensação que os alunos possuem com a presença do professor. Portanto, deve-se incluir encontros presenciais para mesclar o potencial pedagógico que as TIC proporcionam ao ensino e a sala de aula, induzindo o estreitamento de laços na relação aluno-professor e aluno-aluno.

\subsection{Análise dos Questionários Respondidos pelos Professores}

Apenas cinco professoras (Inglês / Espanhol) devolveram os questionários respondidos. De acordo com os questionamentos dos professores, observa-se que eles seguiam o livro didático, como também investiam em atividades para o Exame Nacional do Ensino 
VII Congresso Brasileiro de Informática na Educação (CBIE 2018)

Anais dos Workshops do VII Congresso Brasileiro de Informática na Educação (WCBIE 2018)

Médio (ENEM) e vestibular. No entanto, encontravam vários obstáculos no cumprimento do seu plano, tais como: carga horária insuficiente, falta de materiais, excesso de eventos na escola, e, principalmente, o desinteresse por parte do aluno.

Adicionalmente, identificou-se que os recursos utilizados com maior frequência nas disciplinas de línguas eram: quadro branco, pincel, livro didático, dicionário e, de forma esporádica, computador, data show, celular e pesquisa na internet. Essa realidade acontece, pois, os professores não possuíam tempo suficiente para explorar melhor as habilidades necessárias à aprendizagem de um idioma. Desse modo, a inserção das novas tecnologias não era muito empregada no dia a dia em sala de aula, contudo um dos participantes afirmou o interesse em criar grupos de estudo no Facebook.

Assim, ao analisar as respostas dos professores, nota-se que o uso das TIC fazia diferença no comportamento dos alunos, apesar de não serem unânimes, alguns alunos deixam claro o interesse ao participar das aulas que as novas tecnologias proporcionam. Esse interesse havia sido identificado anteriormente por [Finardi e Veronez 2013]. Um fator negativo que pode ser detectado para o entendimento de uma segunda língua foi a falta de incentivo, de importância dada ao idioma, seguido do número de aulas semanais insuficiente. Mesmo assim, ao colocar o aluno para ser protagonista desse aprendizado, percebeu-se maior envolvimento e dedicação na aprendizagem da língua estrangeira.

Observou-se também, que a maioria dos professores não possuía a formação para utilizar as TIC, mas que as usavam por experiência própria. Eles eram conscientes de que o professor da atualidade deveria conhecer e utilizar os recursos para atrair os alunos e tornar as aulas mais atrativas. Além disso, os docentes afirmaram que essas ferramentas tecnológicas contribuem bastante para a aprendizagem dos alunos; além de motivá-los pelo uso do áudio, do vídeo, de possibilitar a interatividade com a cultura estrangeira, pela economia de tempo no momento da exposição dos conteúdos e por fazê-la de forma dinâmica. Vale ressaltar que esse resultado complementa o argumento de [Silva 2014] em relação à necessidade de os professores considerarem o uso da tecnologia no processo de ensino e aprendizagem.

Apesar dos professores considerarem as TIC, o uso de comunidade e outras plataformas como aliados do professor, esses recursos não eram utilizados normalmente. Os docentes evidenciaram a excelência das ferramentas, até porque permitiam que os alunos aprendessem na prática, que interagissem com professores e colegas, compartilhassem conteúdos, e acreditavam que a variedade de recursos era fundamental para uma aprendizagem eficiente.

Entretanto, conclui-se que os professores tinham conhecimento de todos os benefícios que as TIC poderiam trazer ao âmbito educacional, principalmente, na aprendizagem de uma segunda língua, mas não utilizavam a comunidade específica no Facebook para o estudo de um idioma, apenas utilizavam a internet para pesquisar jogos didáticos para diversificar e dinamizar suas aulas. Com isso, privavam-se de vários recursos que poderiam contribuir para melhorar o processo de ensino e aprendizagem.

\section{Considerações Finais}

O ensino de línguas no Brasil não é visto como uma prioridade. Por meio do seu histórico, percebe-se que vários obstáculos contribuem para que o aluno não atinja uma 
aprendizagem satisfatória. Neste contexto, as TIC surgem como uma nova possibilidade na educação, criando novas expectativas, em virtude de seus grandes benefícios trazidos para diferentes áreas da sociedade. Com isso, surge também a necessidade de modificar a forma de ensinar e de aprender, cabendo ao professor modificar sua metodologia, tornar-se um pesquisador, um conhecedor das novas tecnologias que evolui em uma velocidade incrível, bem como intermediar o aluno na busca de conhecimento. Assim, o aluno deixa de ser o receptor e passa a ser um produtor, um colaborador, interagindo e buscando novos caminhos para sua aprendizagem.

Desta forma, acreditando na potencialidade das TIC e no interesse que os jovens têm por essas tecnologias, em especial, as redes sociais (Facebook), criou-se uma comunidade de línguas estrangeiras (Inglês/Espanhol) para que os alunos pudessem compartilhar arquivos, links e outros materiais com seus colegas, manter uma interação, de modo que acrescentasse saberes a esses idiomas, pelas facilidades e possibilidades que esses recursos tecnológicos oferecem para o processo de ensino e aprendizagem.

As redes sociais são ambientes que podem ser adaptados de acordo com a necessidade de alunos e professores para juntos construírem e descobrirem a melhor maneira de aprender, trocar informações, saberes, ampliar seus horizontes. Um espaço propício para manter um vínculo mais afetivo e produtivo, dando ao professor oportunidade de conhecer melhor seus alunos, suas necessidades e possibilidades para uma melhor adequação da sua prática pedagógica.

Tanto os pesquisadores citados ao longo do trabalho, como o resultado da pesquisa apontam para o potencial que essas ferramentas oferecem quando utilizadas pedagogicamente. Entretanto, em virtude do tempo limitado do experimento e por não haver o hábito dos alunos e professores utilizarem a rede social Facebook com fins educacionais, não houve um envolvimento nem uma exploração dos recursos como se esperava. Assim, refletiu-se a possibilidade de dar continuidade a essa pesquisa por meio da exploração mais intensidade essa ferramenta no processo de ensino e aprendizagem. Além disso, sugere-se a utilização do Facebook para auxiliar no processo de ensino e aprendizagem de outras disciplinas, seguindo a metodologia descrita nesse trabalho.

\section{Agradecimentos}

Os autores agradecem aos alunos da Escola de Ensino Médio Eunice Maria de Sousa Freitas e aos professores das escolas estaduais de Mauriti/CE por participarem voluntariamente da presente pesquisa.

\section{Referências}

Berwanger, A. M. L. e Sabadi, M. N. (2014) Facebook como ferramenta midiática no ensino da língua inglesa. In: Cadernos PDE. Os desafios da escola pública paranaense na perspectiva do professor PDE. Paraná, 2014.

Brasil. (1996). Lei ${ }^{\circ} .9394$, de 20 de dezembro de 1996. Estabelece as diretrizes e bases da educação nacional. Diário Oficial da União, Brasília.

Brasil (1998). Secretaria de Educação Fundamental. (1998). Parâmetros curriculares nacionais: terceiro e quarto ciclos do ensino fundamental: língua estrangeira / Secretaria de Educação Fundamental. Brasília: MEC/SEF, 120 p. 
VII Congresso Brasileiro de Informática na Educação (CBIE 2018)

Anais dos Workshops do VII Congresso Brasileiro de Informática na Educação (WCBIE 2018)

Chapelle, Carol A. (2003) Calico at Center Stage: Our Emerging Rights and Responsibilities. CALICO Journal, 23 (1), p-p 5-15. Iowa State University, 2005.

Faria, H. de O. e Silva, L. de O. (2012). Redes sociais na sala de aula: possibilidades. $1^{\text {a }}$ ed. São Paulo: Edições SM, Cap. 7.

Finardi, K.; Prebianca, G e Momm, C. (2013). Tecnologia na Educação: o caso da Internet e do Inglês como Linguagens de Inclusão. Revista Cadernos do IL, vol. 46, 2013. p. 193-208.

Finardi, Kyria e Veronez, Thiago. (2013). Beliefs on the use of facebook as a communication tool between teachers and students. In: Revista (Con)textos Linguísticos. Espírito Santo, v. 7, n. 8.1, p.292-311, 2013.

Joaquim, B. dos S. (2014) O facebook como ferramenta de aprendizagem colaborativa: o compartilhamento de conhecimento em grupo de estudantes de Ensino Médio em rede. In Simpósio Internacional de Educação a Distância, 2014.

Leffa, V. J. (2014). O ensino de línguas estrangeiras no contexto nacional. Contexturas, APLIESP, n. 4, p. 13-24, 1999. http://www. leffa.pro.br/textos/trabalhos/oensle.pdf.

Mattar, João. (2013). Web 2.0 e redes sociais na educação a distância: cases no Brasil. LaEduc@cion, revista digital, maio, nº145.

Minhoto, P. M. L. V. (2012) A utilização do Facebook como suporte à aprendizagem da biologia: estudo de caso numa turma do $2^{\circ}$ ano. 2012. 122f. Dissertação (Mestrado em Ensino das Ciências) - Instituto Politécnico de Bragança, Bragança, Portugal.

Moran, J. M., Masetto, M. T. e Behrens, M. A. (2000). Novas tecnologias e mediação pedagógica. $1^{a}$ ed. Campinas: Papiurus.

Parâmetros Curriculares Nacionais-Ensino Médio: língua estrangeira. (2000). Brasília: $\mathrm{MEC} / \mathrm{SEF}$.

Patrício, R. e Gonçalves, V. (2010) Facebook: rede social educativa? In I Encontro Internacional TIC e Educação. Lisboa: Universidade de Lisboa, Instituto de Educação.

Richardson, R. J. (1999) Pesquisa Social: Métodos e técnicas. 3. ed. rev. e ampl. São Paulo: Atlas, 1999.

Silva, E. T. (2014) O ensino de língua espanhola mediado pelas novas tecnologias: da sala de aula ao facebook. In: Texto Livre: Linguagem e tecnologia. Belo Horizonte, v.7, n.2, p. 76-85, 2014.

Sturgeon, C. e Walker, C. (2013) Faculty on Facebook: Confirm or Deny? Disponível em: $<$ http://www.cmsturgeon.com/itconf/facebook-report.pdf $>$. Acessado em 20 mai. 2018.

Tajra, S. F. (2002) Comunidades virtuais: um fenômeno na sociedade de conhecimento. São Paulo: Érica.

Warschauer, M. (2014). Computer-assisted language learning: An introduction. In S. Fotos (Ed.) Multimedia language teaching (pp. 3-20). Tokyo, Japan: Logos International. 1996. http://www.ict4lt.org/en/warschauer.htm 